Supporting Information

\title{
Nile Red nucleoside: Design of a solvatofluorochromic nucleoside as an indicator of micropolarity around DNA
}

Akimitsu Okamoto, ${ }^{*}$ Kazuki Tainaka and Yoshimasa Fujiwara

Department of Synthetic Chemistry and Biological Chemistry, Faculty of Engineering, Kyoto University Kyoto 615-8510, Japan

- Copies of ${ }^{1} \mathrm{H} /{ }^{13} \mathrm{C} /{ }^{31} \mathrm{P} \mathrm{NMR}$

Page S2, the ${ }^{1} \mathrm{H}$ NMR of compound 4.

Page S3, the ${ }^{13} \mathrm{C}$ NMR of compound 4.

Page $\mathrm{S} 4$, the ${ }^{1} \mathrm{H}$ NMR of compound 1.

Page S5, the ${ }^{13} \mathrm{C}$ NMR of compound 1.

Page S6, the ${ }^{1} \mathrm{H}$ NMR of the tritylated product of compound 1 (precursor of 5).

Page S7, the ${ }^{13} \mathrm{C}$ NMR of the tritylated product of compound 1 (precursor of 5).

Page S8, the ${ }^{1} \mathrm{H}$ NMR of compound 5.

Page S9, the ${ }^{13} \mathrm{C}$ NMR of compound 5.

Page S10, the ${ }^{31} \mathrm{P}$ NMR of compound 5. 


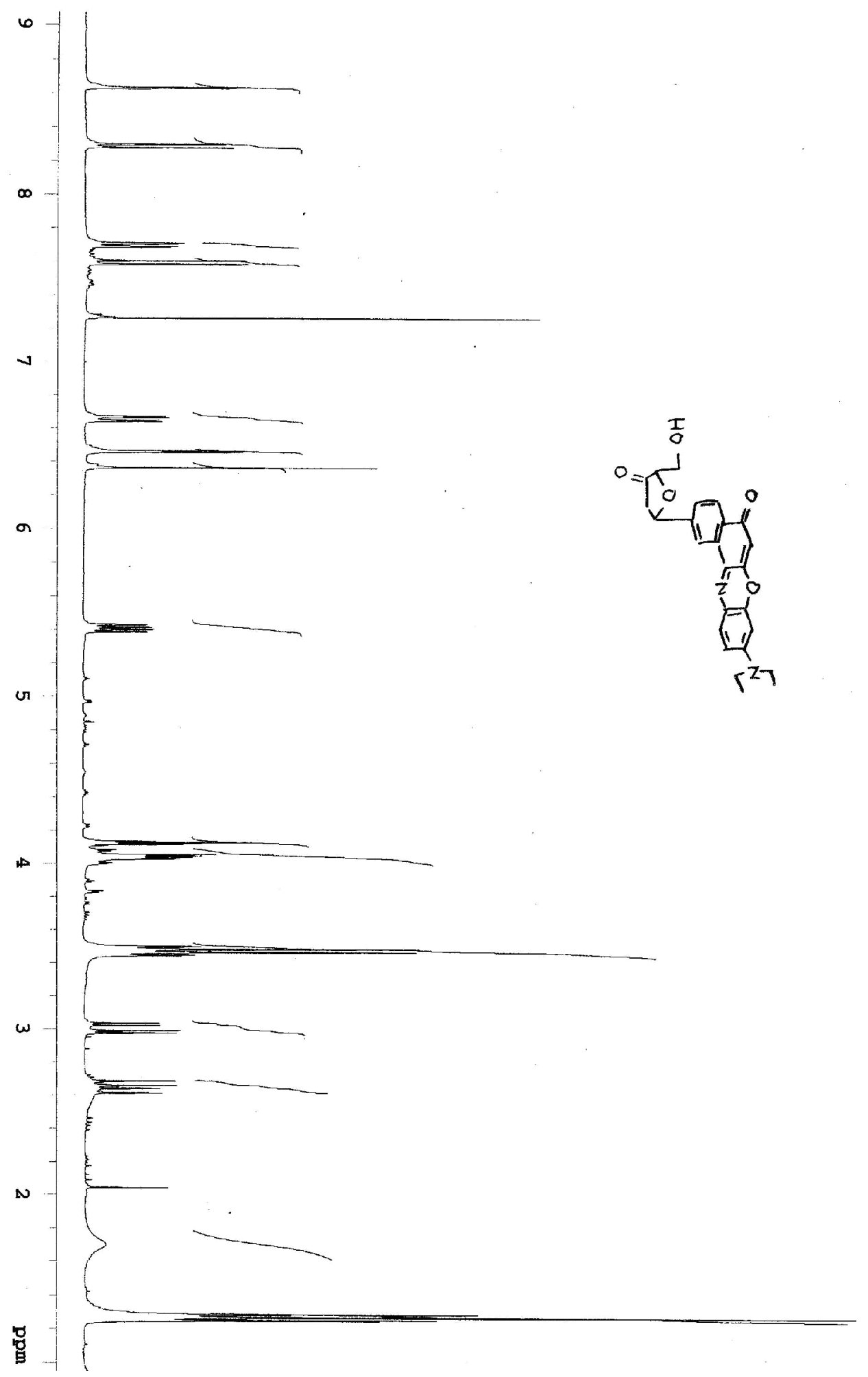




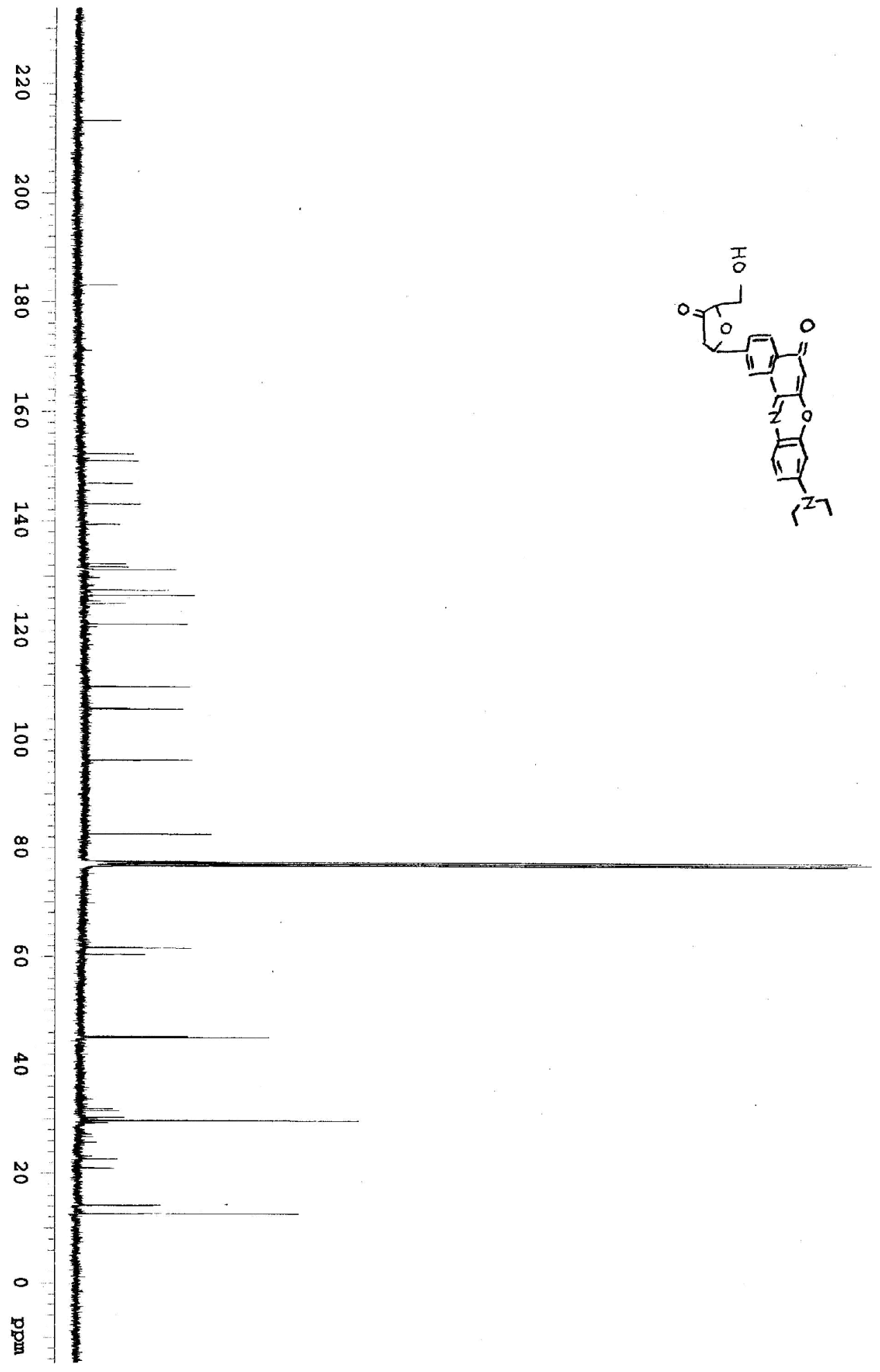




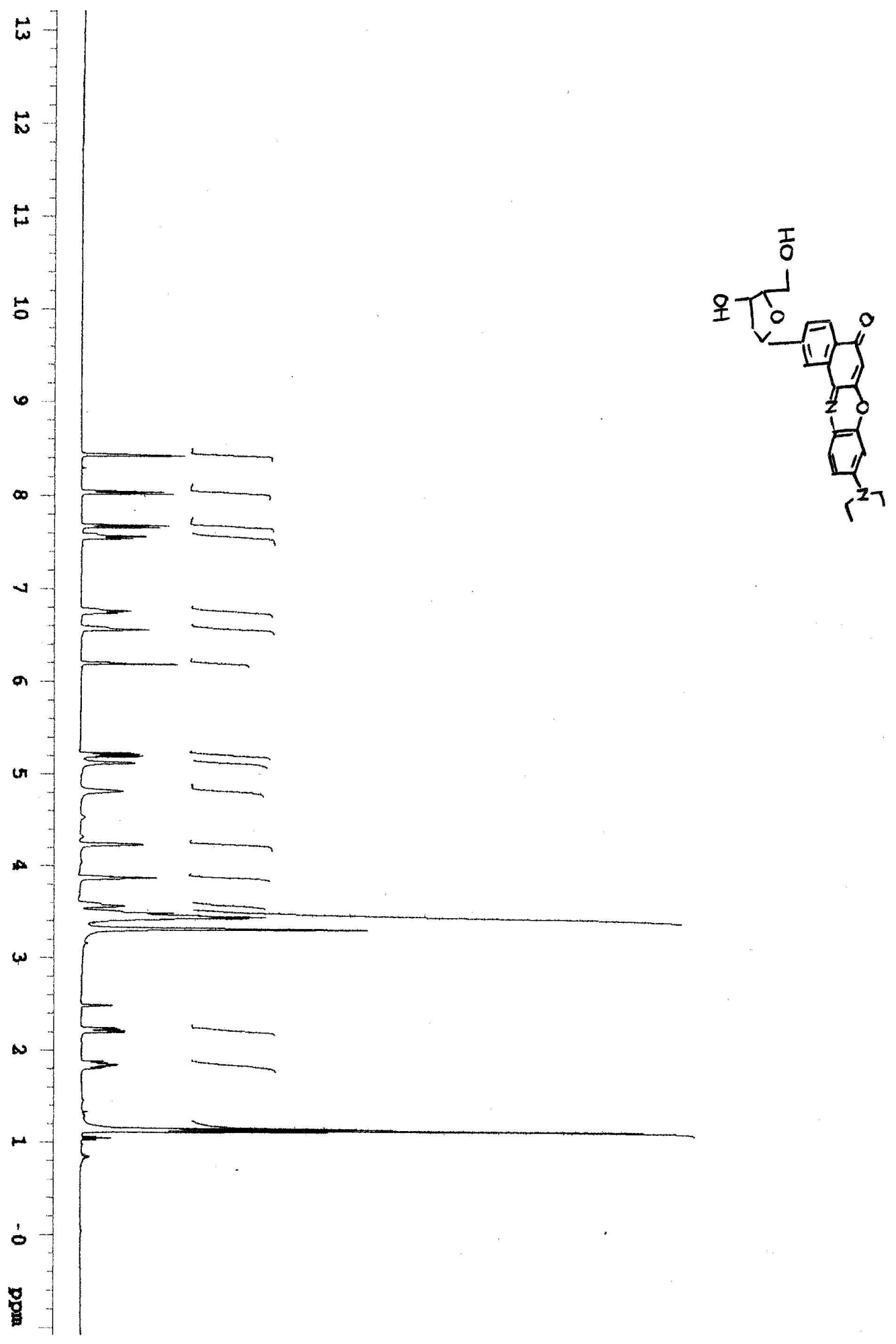




$$
L
$$




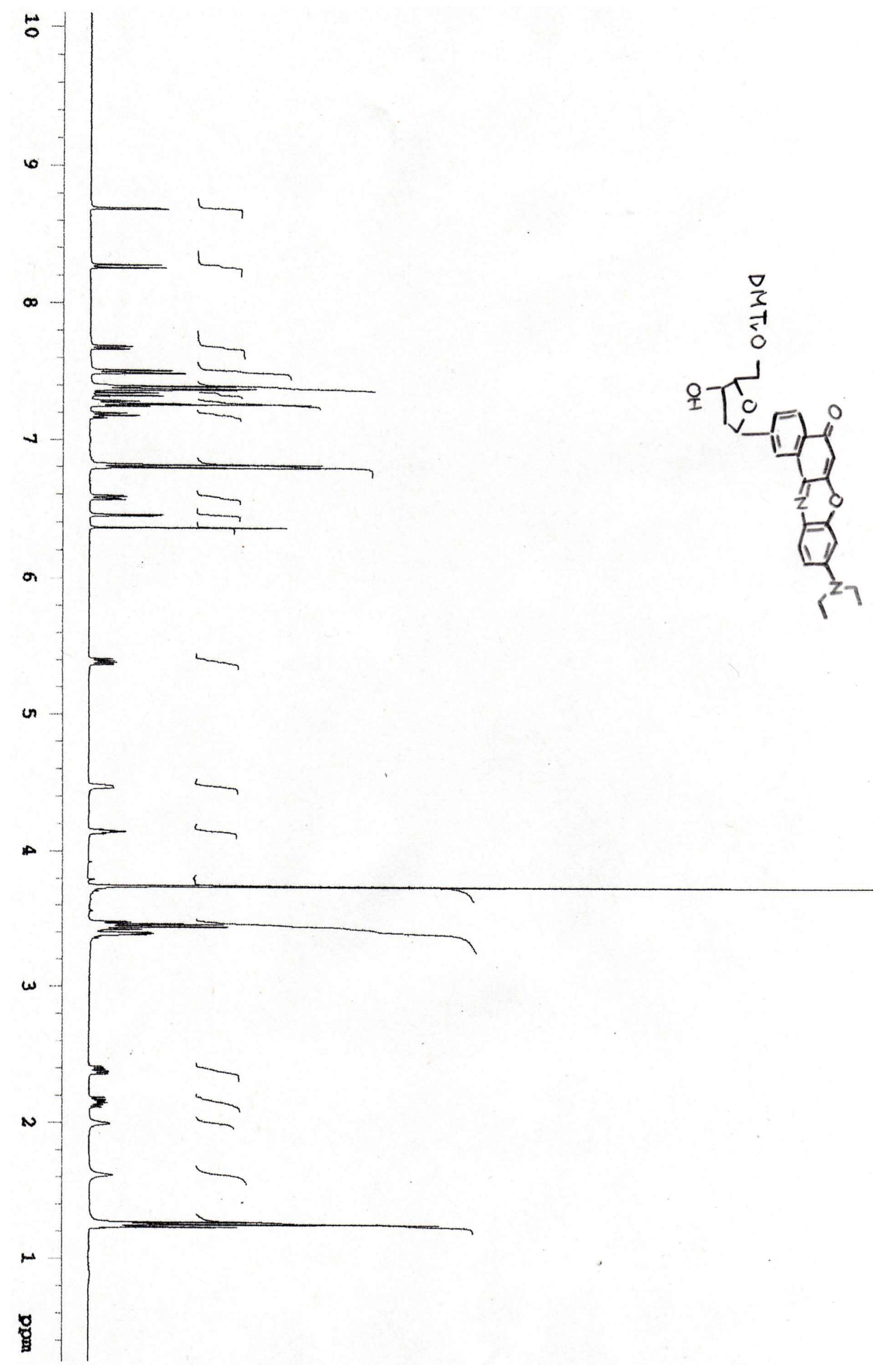




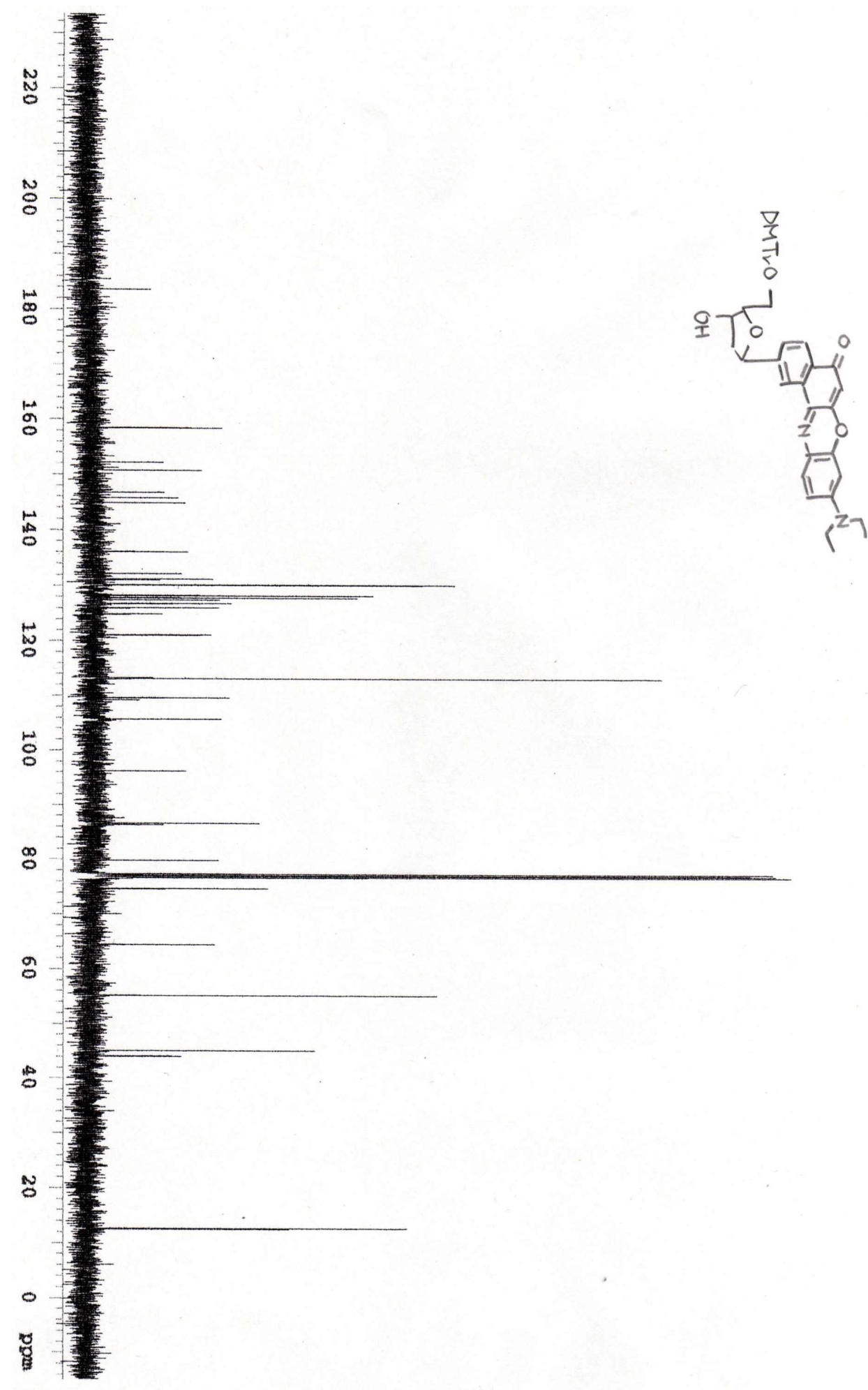




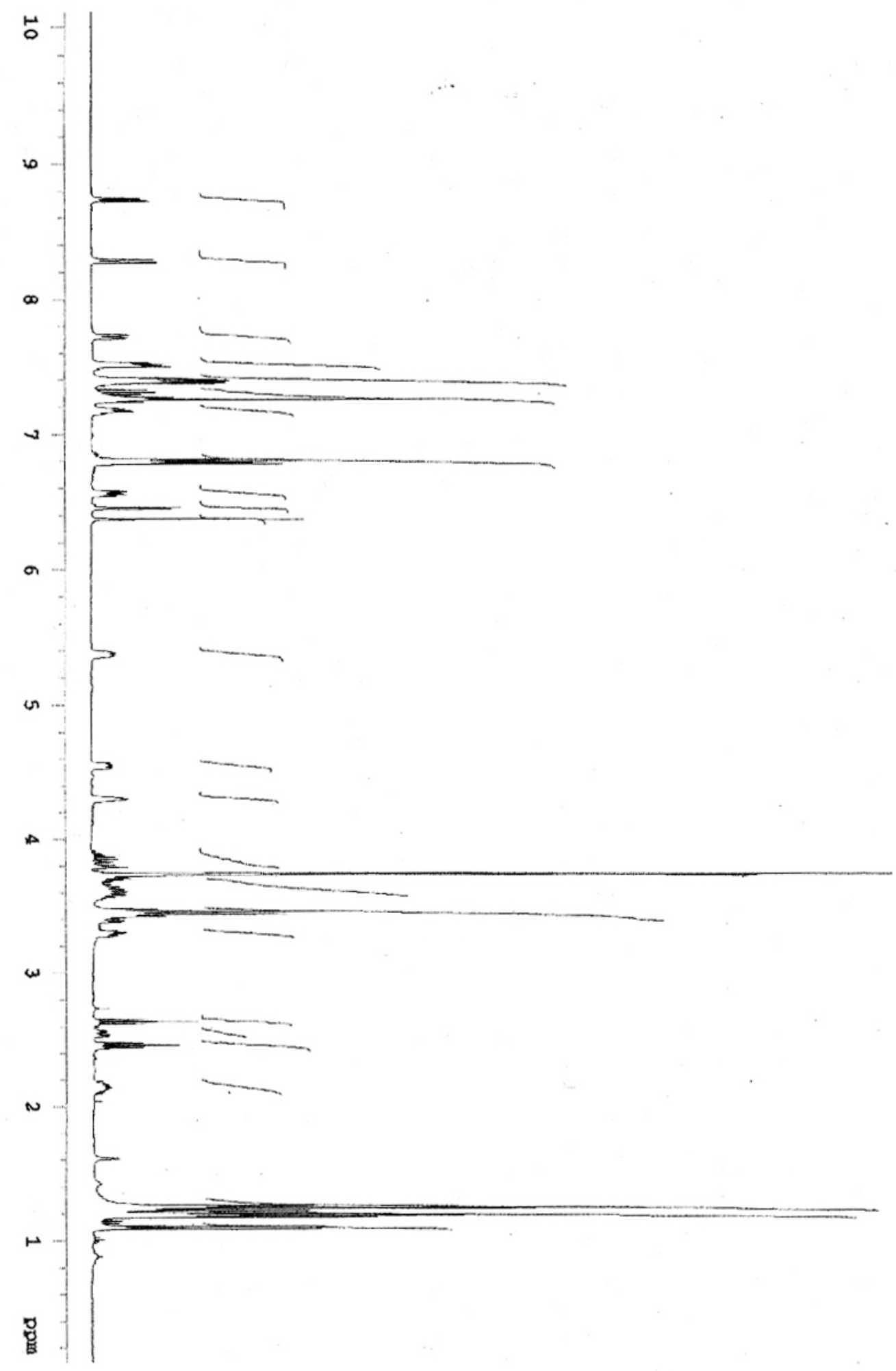




$$
\text { | }
$$




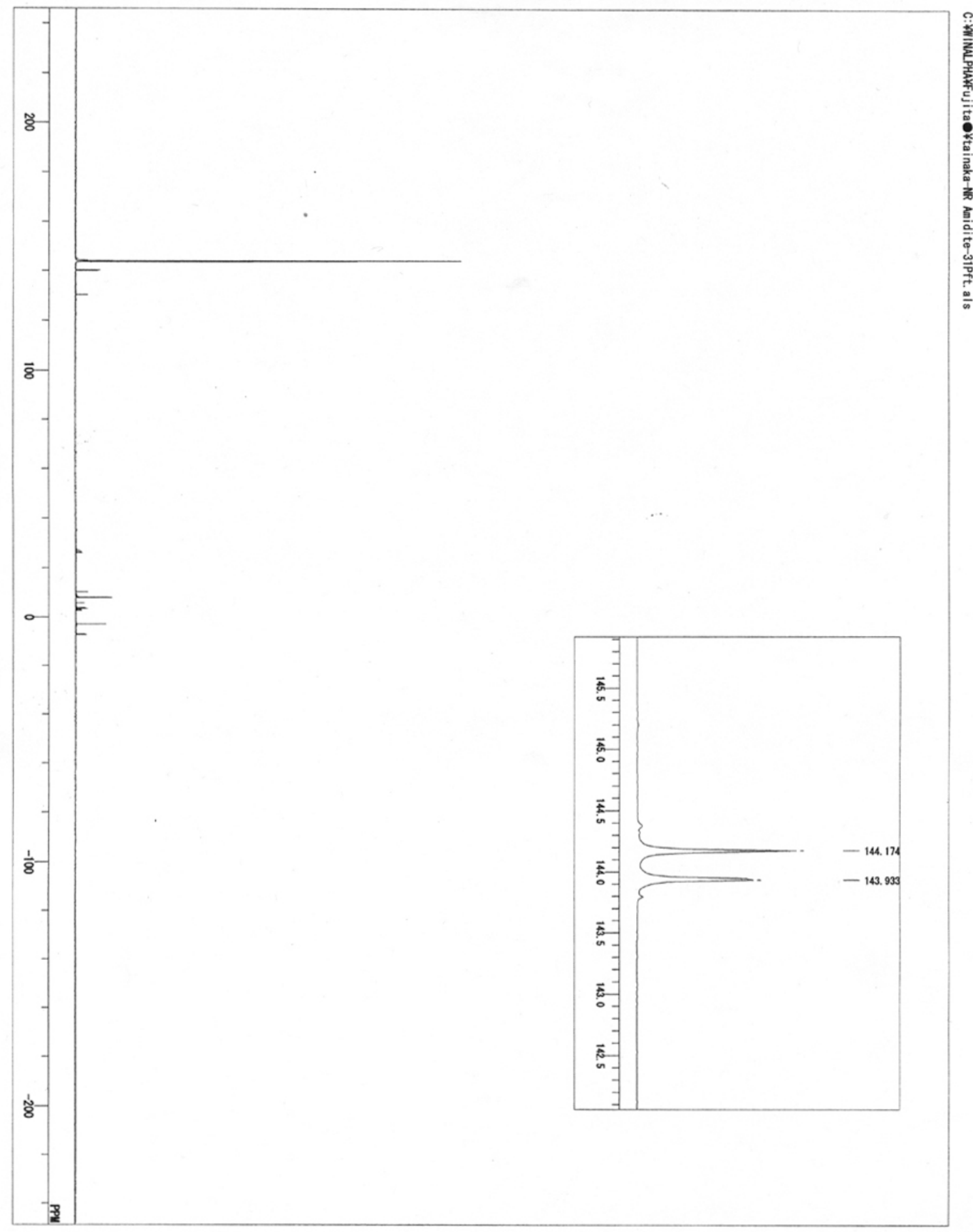

